\title{
PENGARUH PENGETAHUAN, SIKAP DAN KONDISI LINGKUNGAN KERJA TERHADAP PERSEPSI PENERAPAN KESELAMATAN DAN KESEHATAN KERJA
}

\author{
Arief Hartono ${ }^{1}$, Sutopo ${ }^{2}$ \\ Pendidikan Teknik Mesin Fakultas Teknik Universitas Negeri Yogyakarta \\ Email: arevrev@gmail.com
}

\begin{abstract}
The aims of the study are to find out the influence of the following factors to the occupational health and safety (OHS) implementation perception: knowledge, attitude, working environment conditions, and all the three factors together. This research used ex-post facto method. The population is 95 students. Data were collected using tests, questionnaire, and observation. Data were analyzed using regression analysis. The results show these following influences to the OHS implementation perception: knowledge $5.6 \%$, attitude $7 \%$, and working environment conditions $8.3 \%$. The combined knowledge, attitude, and working environment conditions has influence to the OHS implementation perception by $15.2 \%$.
\end{abstract}

Keywords: knowledge, attitude, working environment conditions, ocupational health and safety

\begin{abstract}
ABSTRAK
Penelitian ini bertujuan untuk mengetahui pengaruh pengetahuan terhadap persepsi penerapan keselamatan dan kesehatan kerja, pengaruh sikap, kondisi lingkungan kerja, pengetahuan terhadap persepsi penerapan K3. Penelitian ini menggunakan metode ex- post facto. Populasi penelitian ini berjumlah 95 siswa. Teknik pengumpulan data menggunakan tes, kuesioner dan observasi. Teknik analisis data menggunakan analisis regresi. Hasil penelitian menunjukkan pengetahuan berpengaruh terhadap persepsi penerapan K3 sebesar 5,6\%. Sikap berpengaruh positif terhadap persepsi penerapan K3 sebesar 7\%. Kondisi lingkungan kerja berpengaruh positif terhadap persepsi penerapan K3 sebesar 8,3\%. Pengetahuan, sikap dan kondisi lingkungan kerja secara bersamasama berpengaruh terhadap persepsi penerapan K3 sebesar 15,2\%.
\end{abstract}

Kata kunci: pengetahuan, sikap, kondisi lingkungan kerja, keselamatan dan kesehatan kerja

\section{PENDAHULUAN}

Tahun 2020 merupakan dimulainya persaingan pasar bebas World Trade Organization (WTO) dan General Agreement on Tariffs and Trade (GATT). Untuk dapat bersaing dalam pasar bebas terdapat prasyarat yang ditetapkan oleh The International Standarization Organization (ISO) sebagai badan standarisasi internasional, yaitu tuntutan penerapan Keselamatan dan Kesehatan Kerja (K3). Indonesia termasuk salah satu negara yang ikut berpartisipasi dalam pasar bebas tersebut, oleh karenanya perlu melaksanakan sistem manajemen penerapan K3 di segala bidang yang terkait.
Pembangunan di Indonesia semakin berkembang seiring dengan kemajuan ilmu pengetahuan dan teknologi. Hal ini diikuti pula pada sektor industri yang menggunakan teknologi maju untuk membantu terciptanya efisiensi dan efektifitas pekerjaan sehingga menghasilkan produk berkuantitas yang berkualitas. Penerapan K3 menjadi salah satu faktor yang penting dalam terciptanya efisiensi dan efektifitas dalam pekerjaan.

Penerapan K3 di Indonesia masih belum maksimal. Direktur Keuangan Badan Penyelenggara Jaminan Sosial Ketenagakerjaan, Herdy Trisanto mengatakan bahwa angka kecelakaan kerja di Indonesia mencapai 8.900 
kasus dari Januari sampai April 2014. Menurut Kepala Seksi Pengawasan Norma Ergonomi dan Lingkungan Kerja, Kementerian Ketenagakerjaan, Muhammad Fertiaz, berdasarkan data dari BPJS Ketenagakerjaan, jumlah kasusnya mencapai 105.182 kasus dengan korban jiwa mencapai 2.375 orang pada tahun 2015.

Undang-undang Nomor 1 Tahun 1970 tentang keselamatan dan kesehatan kerja, menyebutkan bahwa keselamatan dan kesehatan kerja merupakan suatu upaya pemberian perlindungan kepada tenaga kerja dan orang lain dari potensi yang dapat menimbulkan bahaya, yang berasal dari mesin-mesin pesawat, alat kerja dan bahan, beserta energi, juga perlindungan dari bahaya lingkungan kerja, sifat perkerja, cara kerja, dan proses produksi. Sutrisno dan Kusmawan, R (2007: 7), menyatakan bahwa keselamatan kerja adalah sebagian ilmu pengetahuan yang penerapannya sebagai unsur-unsur penunjang seorang agar selamat saat sedang bekerja dan setelah mengerjakan pekerjaannya. Faktor peninjauan dan peningkatan kinerja K3 perlu dilakukan untuk menjamin kesesuaian dan efektivitas penerapan sesuai Sistem Manajemen K3 (Nur Hidayat, 2016).

Tenaga kerja Indonesia diharapkan memiliki kompetensi agar mampu bersaing di era globalisasi. Sumber Daya Manusia (SDM) yang handal, kompeten dibidangnya, dan dapat menerapkan semua ilmu yang diperolehnya tentu dapat membuat suatu usaha atau industri berkembang dan mempunyai daya saing yang baik atas kualitas produk atau jasa yang dihasilkan. Salah satu wujud kedisiplinan tenaga kerja adalah menerapkan K3 agar kecelakaan kerja dapat seminimal mungkin dihindari (Ragil Kumoyo Mulyono, 2015).

Pendidikan memiliki andil dalam menanggulangi kecelakaan kerja. Sekolah Menengah Kejuruan (SMK) merupakan pendidikan menengah yang mendidik siswanya untuk siap bekerja dalam bidang tertentu. Diharapkan melalui SMK siswa memiliki persepsi penerapan K3 sedini mungkin sehingga dapat terbentuk persepsi yang positif sebagai landasan berperilaku dalam penerapan K3. SMK sebagai tempat pembentukan sumber daya manusia yang terampil harus berusaha untuk menghasilkan tenaga kerja yang terampil sesuai dengan kebutuhan industri tanpa mengabaikan standar kesehatan dan keselamatan kerja (Beni Suseno, 2016).

Hasil pengamatan yang dilakukan di salah satu SMK di Wonosari menunjukkan bahwa penerapan K3 belum mendapatkan perhatian yang memadai dari semua pihak. Siswa belum sadar pentingnya penerapan K3. Siswa melaksanakan praktik tanpa melihat teori terlebih dahulu sehingga pengetahuan siswa menjadi terbatas dan tidak mengetahui bagaimana prosedur kerja yang benar. Siswa merasa kurang praktis apabila praktik menggunakan peralatan keselamatan kerja. Minimnya poster atau gambar tentang keselamatan dan kesehatan kerja pada area bengkel pemesinan.

Heinrich (1931) dalam Robbins, S. P. (2009: 171) menjelaskan bahwa manusia menjadi faktor penting dalam terjadi kecelakaan, 88\% kecelakaan terjadi disebabkan oleh faktor manusia yang melakukan perilaku yang tidak aman dan atau potensi bahaya mekanik dan fisik. Faktor manusia digambarkan sebagai sifat melamun, ketidakhati- hatian/ kelalaian, dan tidak mengikuti ketentuan- ketentuan keselamatan (Suma'mur, 1985: 45). Benyamin Bloom (1908) membagi perilaku ke dalam 3 domain yaitu cognitive domain, afektif domain, psychomotor domain. Ketiga domain itu diukur dari pengetahuan, sikap, praktik atau tindakan (Notoatmodjo, 1997: 93). Persepsi di pengaruhi pengetahuan, sikap, dan kondisi lingkungan. Persepsi terhadap K3 yang memuat konsep dan tata aturan kerja yang bertujuan untuk melindungi individu, orang lain dan lingkungannya terhadap bahaya kecelakaan dan penyakit akibat kerja.

Sugihartono (2007: 8) mengemukakan bahwa persepsi adalah kemampuan otak dalam 
menerjemahkan stimulus atau proses untuk menerjemahkan stimulus yang masuk ke dalam alat indera manusia. Persepsi terhadap K3 yang memuat konsep dan tata aturan kerja yang bertujuan untuk melindungi individu, orang lain dan lingkungannya terhadap bahaya kecelakaan dan penyakit akibat kerja. Pengetahuan merupakan hasil dari tahu, dan ini terjadi setelah orang melakukan penginderaan terhadap suatu objek tertentu (Notoatmodjo, 1997: 127). Pengetahuan K3 merupakan suatu ilmu berkaitan dengan kesehatan dan keselamatan kerja, meliputi cara pencegahannya, dampak dari kecelakaan dan potensi bahaya kecelakaan kerja. Sikap adalah kecenderungan bertindak dalam menghadapi objek, ide, situasi, dan nilai (Rakhmat, 2003: 39). Alport (1954) dalam Notoatmodjo (1997: 130) mendefinisikan sikap sebagai kesiapan untuk bereaksi terhadap suatu obyek dengan cara- cara tertentu. Sikap K3 merupakan kecenderungan atau kesiapan seseorang untuk melakukan tindakan sesuai dengan ketentuan dan syarat keselamatan dan kesehatan kerja.

Lingkungan kerja adalah sesuatu yang ada disekitar para pekerja dan yang mempengaruhi dirinya dalam menjalankan tugas- tugas yang dibebankan (Nitisemito, 1996: 25). Sedarmayati (2001: 2) mendefinisikan bahwa lingkungan kerja adalah keseluruhan alat perkakas dan bahan yang dihadapi, lingkungan sekitarnya di mana seseorang bekerja, metode kerjanya, serta pengaturan kerjanya baik sebagai perseorangan maupun sebagai kelompok. Berdasarkan Peraturan Menteri Pendidikan Nasional Republik Indonesia Nomor 40 tahun 2008 tentang Standar sarana dan prasarana untuk SMK/MAK, sebuah sekolah terutama SMK harus mempunyai bengkel atau tempat praktik yang memadai.

Pengetahuan, sikap, dan kondisi lingkungan kerja dinilai memiliki peranan penting dalam terbentuknya persepsi penerapan K3 yang menjadi dasar terbentuknya perilaku K3. Oleh karena itu perlu diadakanya penelitian untuk mengetahui pengaruh pengetahuan, sikap dan kondisi lingkungan kerja terhadap persepsi penerapan K3 pada siswa SMK. Sebagai upaya untuk mengetahui tindakan yang sesuai dalam meningkatkan persepsi penerapan K3, sebagai landasan berperilaku dalam penerapan K3.

\section{METODE}

Penelitian ini merupakan penelitian deskriptif dengan menggunakan pendekatan kuantitatif. Metode yang digunankan adalah expost facto data sesuai fakta berdasarkan pengukuran pada responden. Kerangka pemikiran penelitian sebagaimana ditunjukkan pada Gambar 1.

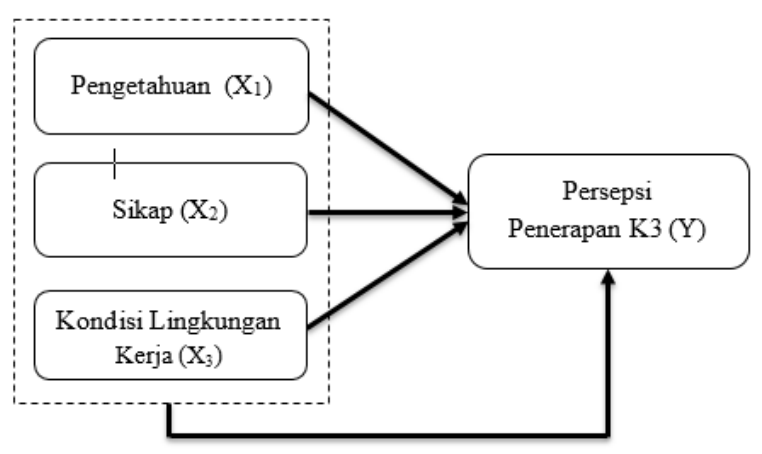

Gambar 1. Kerangka pemikiran penelitian

\section{Penelitian dilakukan di SMKN 2} Wonosari pada bulan September sampai Oktober 2017. Populasi penelitian adalah siswa kelas XI Program Keahlian Teknik Pemesinan SMK N 2 Wonosari yang berjumlah 95 siswa. Prosedur penelitian ini adalah : (1) perumusan maslah, (2) penyusunan kajian teori, penentuan kerangka pikir dan hipotesis penelitian, (3) penentuan subjek penelitian, (5) pengumpulan dan pengelompokan data penelitian, (6) analisis data yang diperoleh, (7) penafsiran dan penarikan kesimpulan dari pembahasan yang dilakukan.

Pengumpulan data menggunakan instrumen berupa tes, kuisioner dan observasi. Tes untuk mendapatkan data pengetahuan K3, kuisioner untuk mendapatkan data persepsi penerapan K3 dan kondisi lingkungan kerja, observasi untuk mendapatkan data sikap K3. Teknik analisis data untuk mendeskripsikan data 
hasil penelitian ini adalah statistik deskriptif meliputi: modus, median, mean, nilai maksimum, nilai minimum dan standar deviasi.

Uji hipotesis pengaruh antar variabel menggunakan regresi linier sederhana, sedangkan analisis jenis data dilakukan uji persyaratan analisis dengan uji normalitas, uji linieritas dan uji multikolinieritas. Analisis data statistik deskriptif, uji persyaratan analisis dan regresi dalam penelitian ini dihitung dengan menggunakan software Statistical Package for Social Sciences (SPSS) versi 23.0.

\section{HASIL DAN PEMBAHASAN}

Persepsi penerapan K3 digambarkan sebagai berikut. Skor tertinggi yang diperoleh siswa adalah 47 dari skor maksimal yang dicapai 48, skor terendah yang diperoleh 33 dari skor minimal yang dapat diraih adalah 12. Selain itu didapatkan nilain mean sebesar 41, Median 41, Modus 40 dan nilai standar deviasi sebesar 3,073. Rangkuman persebaran skor yang diperoleh siswa dapat dilihat pada Tabel 1.

Tabel 1. Persebaran skor pengetahuan

\begin{tabular}{ccc}
\hline Kelas Interval & $F$ & F \% \\
\hline $33-34$ & 3 & 3 \\
$35-36$ & 6 & 6 \\
$37-38$ & 16 & 17 \\
$39-40$ & 22 & 23 \\
$41-42$ & 22 & 23 \\
$43-44$ & 16 & 17 \\
$45-46$ & 9 & 9 \\
$47-48$ & 1 & 1 \\
\hline Jumlah & 95 & $100 \%$ \\
\hline
\end{tabular}

Aspek pengetahuan siswa memperoleh skor tertinggi adalah 18 dari skor maksimal yang dicapai 18, skor terendah yang diperoleh 7 dari skor minimal yang dapat diraih adalah 0 . Nilai mean sebesar 12,74, median 13, modus 12 dan nilai standar deviasi sebesar 2,489. Rangkuman persebaran skor yang diperoleh siswa dapat dilihat pada Tabel 2.
Tabel 2. Persebaran skor pengetahuan

\begin{tabular}{ccc}
\hline Kelas Interval & $\mathrm{F}$ & $\mathrm{F} \%$ \\
\hline $7-8$ & 5 & 5 \\
$9-10$ & 12 & 13 \\
$11-12$ & 28 & 29 \\
$13-14$ & 28 & 29 \\
$15-16$ & 14 & 15 \\
$17-18$ & 8 & 8 \\
$19-20$ & 0 & 0 \\
\hline Jumlah & 95 & $100 \%$ \\
\hline
\end{tabular}

Aspek sikap siswa memperoleh skor tertinggi adalah 43 dari skor maksimal yang dicapai 45, skor terendah yang diperoleh 29 dari skor minimal yang dapat diraih adalah 0 . Selain itu didapatkan nilain mean sebesar 36,59, median 37, modus 36 dan nilai standar deviasi sebesar 3,334. rangkuman persebaran skor yang diperoleh siswa dapat dilihat pada Tabel 3.

Tabel 3. Persebaran skor kedisiplinan siswa

\begin{tabular}{ccc}
\hline Kelas Interval & $\mathrm{F}$ & $\mathrm{F} \%$ \\
\hline $29-30$ & 3 & 3 \\
$31-32$ & 9 & 9 \\
$33-34$ & 15 & 16 \\
$35-36$ & 19 & 20 \\
$37-38$ & 19 & 20 \\
$39-40$ & 18 & 19 \\
$41-42$ & 10 & 11 \\
$43-44$ & 2 & 2 \\
\hline Jumlah & 49 & $100 \%$ \\
\hline
\end{tabular}

Aspek kondisi lingkungan kerja memperoleh skor tertinggi adalah 44 dari skor maksimal yang dicapai 48, skor terendah yang diperoleh 24 dari skor minimal yang dapat diraih 12. Nilai mean sebesar 34,40 , median 34 , modus 35 dan nilai standar deviasi sebesar 4,694. Rangkuman persebaran skor yang diperoleh siswa dapat dilihat pada Tabel 4

Tabel 4. Persebaran skor hasil las SMAW

\begin{tabular}{ccc}
\hline Kelas Interval & $\mathrm{F}$ & $\mathrm{F}(\%)$ \\
\hline $24-26$ & 5 & 5 \\
$27-29$ & 10 & 11 \\
$30-32$ & 18 & 19 \\
$33-35$ & 24 & 25 \\
$36-38$ & 19 & 20 \\
$39-41$ & 11 & 12 \\
$42-44$ & 8 & 8 \\
$45-47$ & 0 & 0 \\
\hline Jumlah & 49 & $100 \%$ \\
\hline
\end{tabular}


Pengaruh pengetahuan terhadap persepsi penerapan K3 ditunjukkan dengan hasil analisis regresi sederhana yang diperoleh nilai koefisien regresi variabel pengetahuan sebesar 0,293 dan nilai konstanta sebesar 36,774. Persamaan regresi dapat dinyatakan sebagai berikut:

$$
\mathrm{Y}=36,774+0,293 \mathrm{X}_{1}
$$

Berdasarkan persamaan tersebut dapat dikatakan jika nilai pengetahuan dinaikkan maka nilai persepsi penerapan K3 naik mengikuti perubahan variabel pengetahuan. Nilai koefisien regresi variabel pengetahuan 0,293 menunjukkan bahwa pengetahuan berpengaruh positif terhadap persepsi penerapan K3. Koefisien korelasi (r) yang terjadi antara pengetahuan terhadap persepsi penerapan K3 sebesar 0,237 dan koefisien determinasi $\left(\mathrm{r}^{2}\right)$ sebesar 0,056. Pengaruh pengetahuan terhadap persepsi penerapan K3 sebesar 8,3\%.

Pengaruh sikap terhadap persepsi penerapan K3 ditunjukkan oleh hasil analisis regresi sederhana diperoleh nilai koefisien regresi variabel sikap sebesar 0,244 dan nilai konstanta sebesar 49,444. Persamaan regresi dapat dinyatakan sebagai berikut:

$$
\mathrm{Y}=49,444+0,244 \mathrm{X}_{2} \ldots \ldots(2)
$$

Berdasarkan persamaan tersebut dapat dikatakan jika nilai sikap dinaikkan maka nilai persepsi penerapan K3 naik mengikuti perubahan variabel sikap. Nilai koefisien regresi variabel sikap 0,244 menunjukkan bahwa sikap berpengaruh positif terhadap persepsi penerapan K3. Koefisien korelasi (r) yang terjadi antara sikap terhadap persepsi penerapan K3 sebesar 0,265 dan koefisien determinasi (r2) sebesar 0,070. Pengaruh sikap terhadap persepsi penerapan K3 sebesar 7\%.

Pengaruh kondisi lingkungan kerja terhadap persepsi penerapan K3 ditunjukkan oleh hasil analisis regresi sederhana diperoleh nilai koefisien regresi variabel kondisi lingkungan kerja K3 sebesar 0,189 dan nilai konstanta sebesar 34,013. Persamaan regresi dapat dinyatakan sebagai berikut:

$$
\mathrm{Y}=34,013+0,189 \mathrm{X}_{3} \ldots \ldots
$$

Berdasarkan persamaan tersebut dapat dikatakan jika nilai kondisi lingkungan kerja dinaikkan maka nilai persepsi penerapan K3 naik mengikuti perubahan variabel kondisi lingkungan kerja. Nilai koefisien regresi variabel kondisi lingkungan kerja 0,189 menunjukkan bahwa kondisi lingkungan kerja berpengaruh positif terhadap persepsi penerapan K3. Koefisien korelasi (r) yang terjadi antara kondisi lingkungan kerja terhadap persepsi penerapan K3 sebesar 0,288 dan koefisien determinasi (r2) sebesar 0,083. Pengaruh kondisi lingkungan kerja terhadap persepsi penerapan K3 sebesar 8,3\%.

Pengaruh pengetahuan, sikap dan kondisi lingkungan kerja terhadap persepsi penerapan K3 ditunjukkan oleh hasil analisis regresi sederhana diperoleh nilai koefisien regresi variabel pengetahuan sebesar 0,219, varibel sikap sebesar 0,158, variabel kondisi lingkungan kerja sebesar 0,147 dan nilai konstanta sebesar 38,435. Persamaan regresi dapat dinyatakan sebagai berikut:

$$
\begin{gathered}
\mathrm{Y}=38,435+0,219 \mathrm{X}_{1}+0,158 \mathrm{X}_{2}+ \\
0,147 \mathrm{X}_{3} \ldots \ldots . .(4)
\end{gathered}
$$

Persamaan tersebut memiliki arti jika nilai semua variabel independen pengetahuan, sikap dan kondisi lingkungan kerja dinaikkan maka nilai persepsi penerapan K3 naik mengikuti perubahan variabel independen. Nilai koefisien korelasi (r) yang terjadi antara pengetahuan, sikap dan kondisi lingkungan kerja terhadap persepsi penerapan K3 sebesar 0,390 dan koefisien determinasi (r2) sebesar 0,152. Pengaruh pengetahuan, sikap dan kondisi lingkungan kerja terhadap persepsi penerapan K3 sebesar 15,2\%. 


\section{SIMPULAN}

Berdasarkan penyajian data dan pembahasan di atas maka dapat disimpulkan bahwa: 1) pengetahuan berpengaruh terhadap persepsi penerapan. Hal ini ditunjukkan dengan

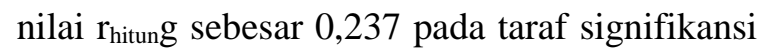
$5 \%$ ( $\left.\mathrm{r}_{\text {hitung }}>\mathrm{r}_{\text {tabel }}\right)$ yaitu 0,237>0,1726 dan $\left(\mathrm{r}_{2}\right)$ sebesar 0,056 atau 5,6\%. Persepsi penerapan K3 dipengaruhi pengetahuan sebesar 5,6\%., 2) Sikap berpengaruh terhadap persepsi penerapan K3. Hal ini ditunjukkan dengan nilai $\mathrm{r}_{\text {hitung }}$ sebesar 0,265 pada taraf signifikansi 5\% ( $\mathrm{r}_{\text {hitung }}>$ $\left.\mathrm{r}_{\text {tabel }}\right)$ yaitu 0,265>0,1726 dan $\left(\mathrm{r}_{2}\right)$ sebesar 0,070 atau 7\%. Persepsi penerapan K3 dipengaruhi sikap sebesar 7\%., 3) Kondisi lingkungan kerja berpengaruh terhadap persepsi penerapan $\mathrm{K} 3$. Hal ini ditunjukkan dengan nilai $r_{\text {hitung }}$ sebesar 0,288 pada taraf signifikansi $5 \%$ dimana $\left(\mathrm{r}_{\text {hitung }}>\right.$ $\left.\mathrm{r}_{\text {tabel }}\right)$ yaitu 0,288>0,1726 dan $\left(\mathrm{r}_{2}\right)$ sebesar 0,083 atau 8,3\%. Persepsi penerapan K3 dipengaruhi kondisi lingkungan kerja sebesar 8,3\% dan 4) Secara bersama- sama pengetahuan, sikap dan kondisi lingkungan kerja berpengaruh terhadap persepsi penerapan K3. Hal ini ditunjukkan dengan nilai $F_{\text {hitung }}$ sebesar 0,390 pada taraf signifikansi $5 \%$ dimana $\left(\mathrm{F}_{\text {hitung }}>\mathrm{F}_{\text {tabel }}\right)$ yaitu $0,390>0,1726$ dan r2 sebesar 0,152 atau 15,2\%. Persepsi penerapan K3 dipengaruhi pengetahuan, sikap dan kondisi lingkungan kerja secara bersama-sama sebesar $15,2 \%$.

\section{DAFTAR RUJUKAN}

Beni Suseno. (2016). Perilaku Siswa Dalam Pelaksanaan Kesehatan dan Keselamatan Kerja Praktek Las Busur Manual di SMK N 3 Yogyakarta. JPVTM, 4 (8), 549- 556.

Depnakertrans. (1970). Undang- Undang RI Nomor, 1 Tahun 1970, Tentang Keselamatan Kerja.

Hedy Trisanto. Angka kecelakaan kerja secara nasional mencapai 8.900 kasus dari Januari hingga April 2014. Diakses pada tanggal 8 Agustus 2017 dari: https://www.antaranews.com/berita/432945 /bpjs-terjadi-8900-kecelakaan-kerjaselama-2014.

Jalaludin Rakhmat. (2003). Pengetahuan Sikap Dalam Perilaku. Jakarta: Widya Medika.

Muhammad Fertiaz. Berdasarkan data dari BPJS Ketenagakerjaan, jumlah kasusnya mencapai 105.1892 kasus pada 2015, dengan korban jiwa mencapai 2.375 orang. Diakses pada tanggal 20 Juli 2017 dari : http://properti.kompas.com/read/2016/11/0/ 9/154736121/kecelakaan.kerja.di.indonesia. tercatat.105.182.kasus.

Nur Hidayat. (2016). Kajian Keselamatan dan Kesehatan Kerja Bengkel di Jurusan Pendidikan Teknik Sipil dan Perencanaan Fakultas Teknik UNY. JPTK, 23 (1), 51- 66.

Permendiknas. (2008). Peraturan Menteri Pendidikan Nasional Nomor 40, Tahun 2008, tentang Standar Sarana dan Prasarana Sekolah Menengah Kejuruan/Madrasah Aliyah Kejuruan (SMK/MAK).

Ragil Kumoyo Mulyono. (2015). Implementasi K3 Pada Praktik Mebubut di SMK Negeri 1 Sedayu. JPVTM, 3 (4), 271- 275.

Robbins, S. P. (2009). Perilaku Organisasi Organizational Behavior. Jakarta: Salemba Empat.

Sedarmayati. (2001). Sumber Daya Manusia dan Produktivitas Kerja. Bandung: Mandar Maju.

Soekidjo Notoatmodjo. (1997). Pengantar Pendidikan Kesehatan dan Ilmu Perilaku Kesehatan. Yogyakarta: Andi Offset.

Sugihartono. (2007). Psikologi Pendidikan. Yogyakarta: FIP UNY.

Suma'mur. (1985). Keselamatan Kerja dan Pencegahan Kecelakaan. Jakarta: Gunung Agung.

Sutrisno, \& Kusmawan, R. (2007). Modul Prosedur Keamanan Keselamatan dan Kesehatan kerja. Jakarta: Yudhistira. 